\title{
Side-to-Side Ileosigmoidostomy Shunting Surgery for the Treatment of Elderly Patients With Chronic Constipation
}

\author{
Yuda Handaya, Agung Maryanto, Marijata \\ Digestive Surgery Division, Department of Surgery, Faculty of Medicine, Universitas Gadjah Mada/Dr. Sardjito Hospital, Yogyakarta, Indonesia
}

Constipation is a digestive disorder that often occurs in the elderly; its main cause is bowel motility disorder. Treatments for patients with chronic constipation include pharmacotherapy, diet changes, and surgery if other therapies do not offer satisfactory results. We describe 4 patients, 2 men (70 and 65 years old) and 2 women (75 and 66 years old), who were diagnosed with chronic constipation (slow transit constipation) and treated with conventional therapy, but did not improve. For that reason, side-to-side ileosigmoidostomy shunting surgery was performed. After the surgery, the average time until normal defecation was 16 days, and the defecation frequency was 3 to 4 times a day with no need for a laxative. No patient had a recurrence of constipation. Based on these results, side-to-side ileosigmoidostomy shunting surgery is expected to restore digestive function and can be considered as an alternative therapy for elderly patients with chronic constipation.

Keywords: Constipation; Colostomy; Defecation; Laxatives; Intestinal diseases

\section{INTRODUCTION}

Constipation is a common gastrointestinal disorder in the elderly. Passage disorder occurs when the stool is hard and difficult to pass. Many studies have estimated the frequency of constipation to be $12 \%-19 \%$. The frequency of constipation increases with increasing age, and constipation is more common in women. In men and women over 65 years of age, the rates of constipation are about $26 \%$ in men and $34 \%$, respectively [1]. Constipation increases with age, decreased mobility, depression, and the use of drugs including opiates. Other research has indicated that constipation is also associated with diabetes mellitus, hypothyroidism, diverticulitis, irritable bowel syndrome, and hemorrhoids [2, 3].

Management of chronic constipation in the elderly is paramount to keeping track of the main causes of constipation. In some cases, associated diseases need to be treated first. Cases involving sec-

Received: April 21, 2017 - Accepted: October 10, 2017

Correspondence to: Yuda Handaya, M.D.

Digestive Surgery Division, Department of Surgery, Faculty of Medicine,

Universitas Gadjah Mada/Dr. Sardjito Hospital, Jl. Kesehatan No. 1

Yogyakarta 55281, Indonesia

Tel: +62-274581333, Fax: +62-274581333, E-mail: yudahandaya@ugm.ac.id

(C) 2017 The Korean Society of Coloproctology

This is an open-access article distributed under the terms of the Creative Commons Attribution NonCommercial License (http://creativecommons.org/licenses/by-nc/4.0) which permits unrestricted noncommercial use, distribution, and reproduction in any medium, provided the original work is properly cited. ondary causes of constipation should be eliminated, so that chronic constipation in the elderly is properly treated. First, a physical examination should be given, and the history of illness should be tracked in detail. Identifying the cause of the constipation is important. In difficult cases, invasive colonoscopy examination can be considered. Furthermore, some cases of chronic constipation in the elderly are connected with the previous use of drugs, such as opioids, beta blockers, calcium channel blockers, diuretics and anticholinergics [2].

Common treatments used in treating patients with chronic constipation include the uses of magnesium hydroxide, polycarbophil, methylcellulose, bisacodyl, and misoprostol lubricants. These are recommended by the American College of Gastroenterology. Certain cases, in which conventional treatments for chronic constipation fail, will require surgical action in the form of a total colectomy with end-to-end anastomosis and end-to-end ileorectal treatment [4]. Herein, we report 4 elderly patients with a diagnosis of chronic constipation due to slow transit constipation (STC) for whom conventional therapy had failed so a decision was made to pursue surgical therapy. In these elderly patients, we considered the duration of surgery, the trauma of surgery, the complications of surgery, the postsurgery care, and the results of surgery, all of which can affect digestive functions. We decided not to perform a subtotal end-to-end colectomy ileorectal anastomosis; rather, we performed a shunting side-to-side ileosigmoidostomy. 


\section{CASE REPORTS}

\section{Case 1}

A 70-year-old man complained of defecation once every 5 days, which had been ongoing for the past 10 years. During that time, the patient could only defecate by consuming 5 Dulcolax tablets per day. Physical examination showed a flat abdomen with no anal plug. The ampulla was not collapsing, and no palpable hard stool or blood mucus on the gloves and no ileus symptoms or signs were observed. The results of the laboratory examinations were typical. The colonoscopy scope penetrated to $35 \mathrm{~cm}$, revealing indication of proctitis and colitis and suggesting chronic nonspecific colitis. Efforts to track underlying diseases showed no other primary diseases. Because no improvement had been seen during conventional treatment, we performed a shunting laparotomy and a side-to-side ileosigmoidostomy. Postsurgery, the patient defecated three to five times a day during the first week. This became normal with good consistency at 2-week postsurgery.

\section{Case 2}

A 65-year-old man came to the hospital with complaints of irregular defecation, i.e., once every 3 days. He complained of constant straining during defecation and a feeling of dissatisfaction after defecation. The patient complained that he was unable to defecate without the use of a laxative. The patient had tried pharmacotherapy, but with no response. On physical examination, the abdomen was found to be flat with no scarring or striae; no tenderness or palpable masses (intraperitoneal and extraperitoneal) and no other peritoneal acquired abnormalities were found. The results of the laboratory examination were normal. Chronic colitis was seen on colonoscopy. No primary underlying disease was found. Because conventional therapy had produced no improvement, surgery using a shunting laparotomy and a side-to-side ileosigmoidostomy was performed. Postsurgery, the patient defecated three to five times every day during the first week; this became normal and was consistent at the first week postsurgery.
Case 3

A 75-year-old woman who was a consulting colleague in gastroenterology came to the surgery clinic with bowel complaints: defecation with straining once every 5 days and a feeling of dissatisfaction after defecation. A lump was in the rectum while straining and that was accompanied by a history of bowel movements of fresh blood. The patient complained that she was unable to defecate without a laxative. Pharmacotherapy had been used for 7 years, but with no response. On physical examination, the abdomen was found to be flat with no scarring or striae; neither tenderness nor palpable masses (intraperitoneal and extraperitoneal) were found. Examination of the rectal plug revealed results in the normal range, as did the laboratory examinations. Ultrasonography photographs of gallstones were obtained along with abdominal photographs of a paralytic ileus. No primary underlying disease was found. Because conventional treatment had provided no relief, surgery with side-to-side shunting in a laparoscopic ileosigmoidostomy and a cholecystectomy were performed. Postsurgery, the patient defecated 5 to 7 times every day during the first week. The patient also used Imodium twice during the first week, and her defecation frequency was normal by 3 -week postsurgery.

\section{Case 4}

A 66-year-old woman came to the hospital with complaints of irregular defecation with straining once every 5 days, a feeling of dissatisfaction after defecation, and a lump in the rectum while straining. She also had a history of bowel movements of fresh blood. The patient complained that she was unable to defecate without a laxative. The patient used pharmacotherapy for 1 year, but with no response. On physical examination, the abdomen was found to be flat with no scars or striae; neither tenderness nor palpable masses (intraperitoneal and extraperitoneal) were found. The examination of the rectal plug showed internal hemorrhoids grades $2-3$. The results of the laboratory examinations were normal, and no primary underlying disease was found. Because conventional treatment had provided no relief, we performed a shunting laparotomy ileosigmoidostomy side-to-side using a lin-

Table 1. Patients' sex, age, diagnosis, surgery, and frequency of defecation before and after surgery

\begin{tabular}{|c|c|c|c|c|c|c|}
\hline \multirow{2}{*}{ Case } & \multirow{2}{*}{ Sex } & \multirow{2}{*}{ Age (yr) } & \multirow{2}{*}{ Diagnosis } & \multirow{2}{*}{ Surgical technique } & \multicolumn{2}{|c|}{ Frequency of defecation } \\
\hline & & & & & Presurgery & Postsurgery (first week) \\
\hline 1 & Male & 70 & Chronic nonspecific colitis & $\begin{array}{l}\text { Laparotomy } \\
\text { Shunting side-to-side ileosigmoidostomy }\end{array}$ & Once every 5 days & 3-5 Times every day \\
\hline 2 & Male & 65 & Chronic colitis & $\begin{array}{l}\text { Laparotomy } \\
\text { Shunting side-to-side ileosigmoidostomy }\end{array}$ & Once every 3 days & 3-5 Times every day \\
\hline 3 & Female & 75 & Chronic constipation with cholelithiasis & $\begin{array}{l}\text { Laparotomy } \\
\text { Shunting side-to-side ileosigmoidostomy } \\
\text { and cholecystectomy }\end{array}$ & Once every 5 days & 5-7 Times every day \\
\hline 4 & Female & 66 & $\begin{array}{l}\text { Chronic constipation with hemorrhoids } \\
\text { grades } 2-3\end{array}$ & $\begin{array}{l}\text { Laparotomy } \\
\text { Shunting side-to-side ileosigmoidostomy } \\
\text { and stapler for a hemorrhoidectomy }\end{array}$ & Once every 5 days & 4 Times every day \\
\hline
\end{tabular}


ear stapler and a stapler with stapled haemorrhoidectomy procedure. Postsurgery, the patient defecated four times daily during the first week. This frequency became consistent 2-week postsurgery.

\section{DISCUSSION}

In these 4 cases (Table 1), the average frequency of bowel movements was once every 4 days with hard stool. The stools consisted of separate hard lump-like nuts (Bristol Stool Chart type 1) [5]. There was no drug use or other underlying cause or need for bed rest. Secondary disease tracking all cases showed no underlying illnesses such as tumors in the colon, no presence of systemic diseases, and no drug use, all of which can cause constipation. We confirmed STC by eliminating the other causes of constipation. STC with bowel movements every 4 to 5 days of separate hard lump-like nuts (Bristol Stool Chart type 1) is due to peristaltic colonic disorders [6]. A careful examination of the history of the disease is required to keep track of the medicines that cause the onset of constipation. This will eliminate the secondary causes of constipation. Some patients may experience constipation of unknown origin, but they usually show no signs and symptoms (are asymptomatic). In cases with severe and unexpected constipation, blood is present in the stool, body weight decreases quickly and is accompanied by fever, and anorexia, nausea, and vomiting occur; patients with a family history of inflammatory bowel disease or colonic tumors, especially those over 50 years of age, require a full examination of the colon [7].

The consistency of the stool and its shape, based on the Bristol Stool Chart, is very useful for assessing the colonic transit time (Fig. 1). Type-1 stool experiences a colonic transit time of 100 hours (slow transit) whereas Type-7 stool experiences a transit
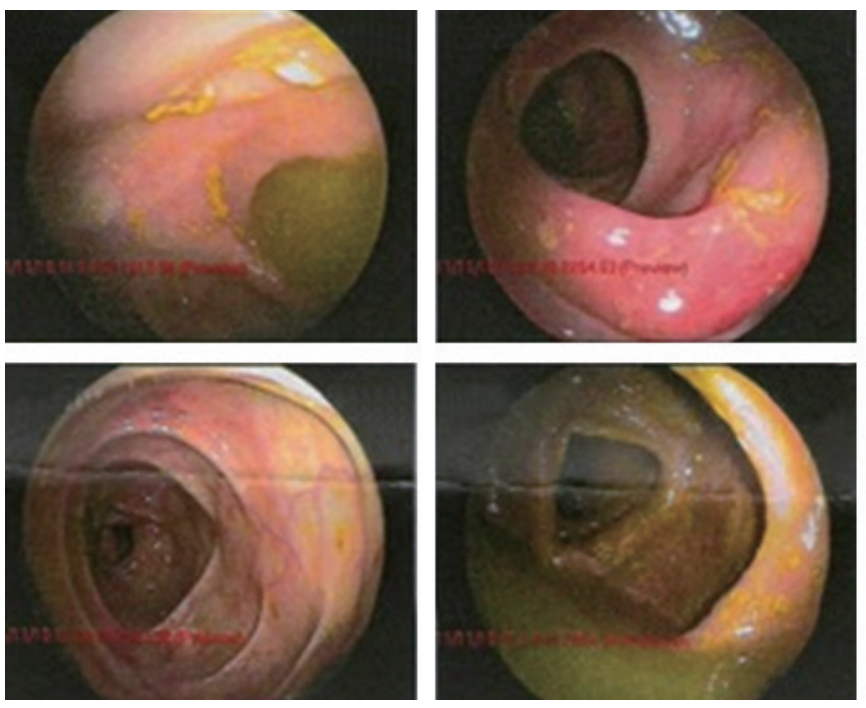

time of approximately 10 hours (rapid transit). The use of the Bristol Stool Chart $[8,9]$ in the assessment of patterns of daily defecation should be matched with fecal output, straining, and inability to withstand defecation [10].

The 4 patients used laxative tablets and oral syrup tablets and syrup. They consumed foods high in fiber such as fruits, and they

\begin{tabular}{|l|l|}
\hline Type I & $\begin{array}{l}\text { Separate hard lumps, like nuts } \\
\text { (hard to pass) }\end{array}$ \\
\hline Type 2 & Sausage-shaped but lumpy \\
\hline Type 3 & $\begin{array}{l}\text { Like a sausage but with cracks on } \\
\text { its surface }\end{array}$ \\
\hline Type 4 & $\begin{array}{l}\text { Soft boft } \\
\text { (passed easily) }\end{array}$ \\
\hline Type 5 & $\begin{array}{l}\text { Fluffy pieces with ragged edges, a } \\
\text { mushy stool }\end{array}$ \\
\hline Type 7 & $\begin{array}{l}\text { Watery, no solid pieces } \\
\text { Entirely Liquid }\end{array}$ \\
\hline
\end{tabular}

Fig. 1. Bristol stool chart.
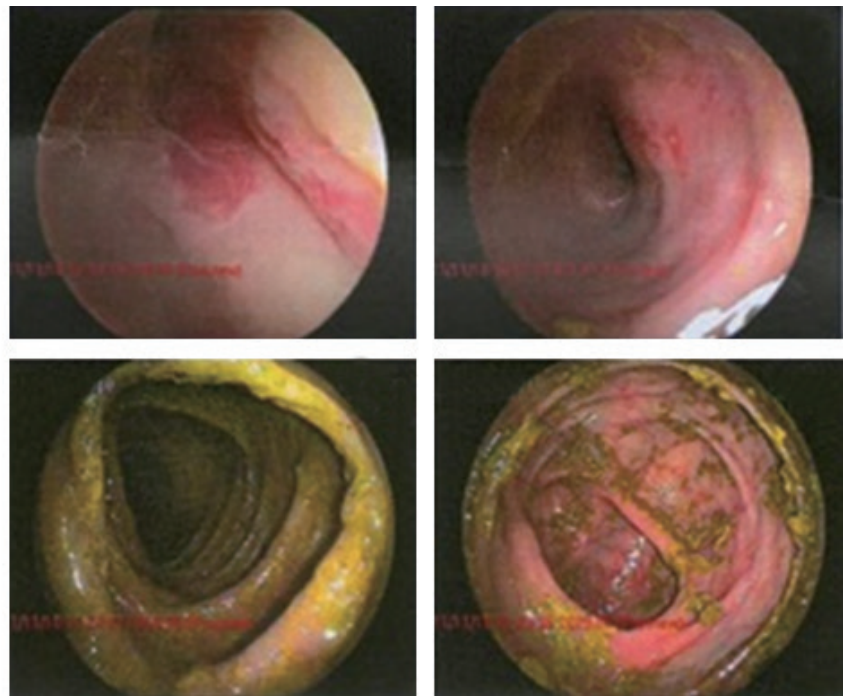

Fig. 2. Colonoscopy revealed the existence of chronic colitis. 


\section{Coloproctology}

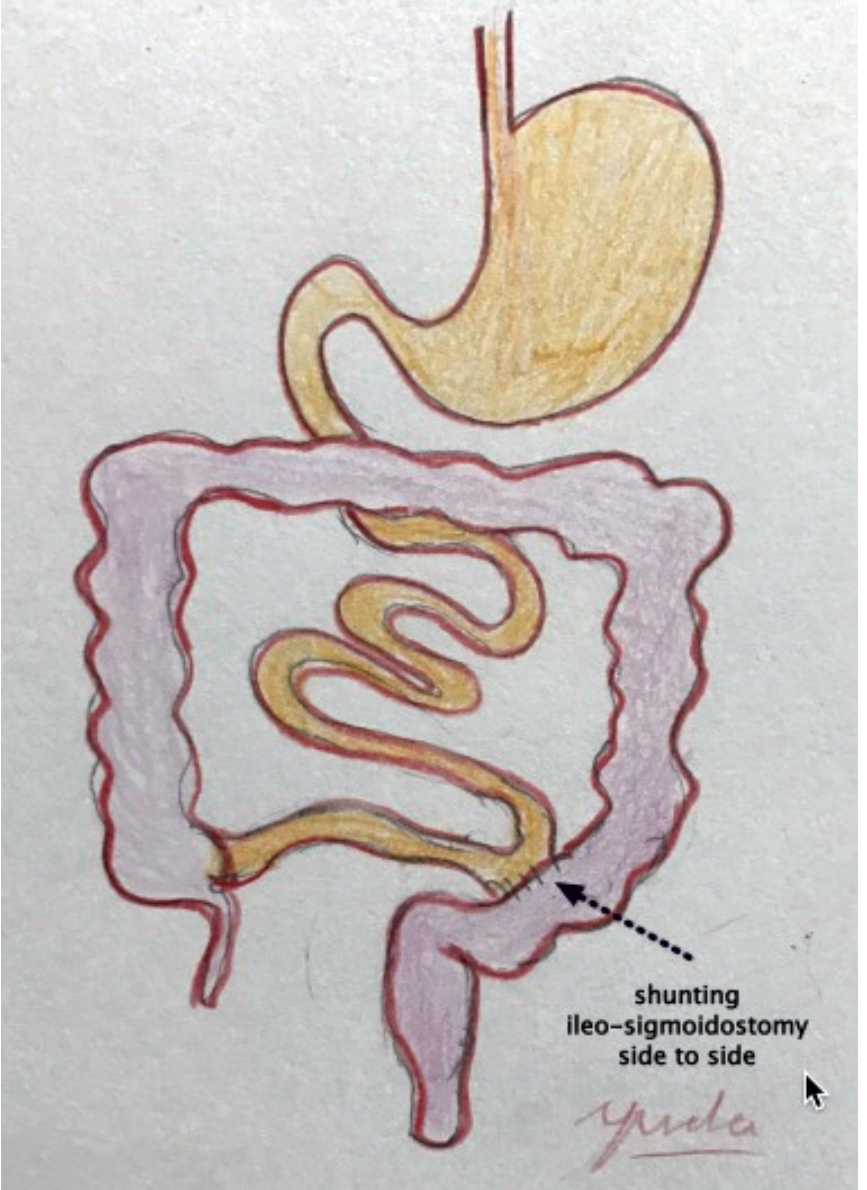

Fig. 3. Shunting side-to-side ileosigmoidostomy.

avoided things that caused constipation like bed rest and physical activity. Conventional treatment had provided no relief for these patients, so they decided to undergo surgery. Examinations with imaging studies were used to rule out the acute processes of colonic ileus (Fig. 2) and to assess the causes of a chronic constipation [11]. In these 4 elderly patients, operating results restored digestive functions, and we decided not to perform a subtotal colectomy ileorectal anastomosis end-to-end, but rather to perform a shunting side-to-side ileosigmoidostomy (Fig. 3).

As a result of the surgery, rather than defecating once every 4 to 5 days, the patients defecated 4 times per day with the consistency of liquid from postsurgery day 1 until postsurgery day 4 . Defecation became normal and the stool was solid by postsurgery day 5 to day 14 . The patients exhibited average defecation by postsurgery day 16; the frequency and the consistency of their bowel movements had returned to normal, 1 to 2 times a day. The pa- tients experienced no complications; furthermore, they no longer had complaints such as abdominal pain and incontinence by the second postsurgery week. A 1-year follow-up with an interview by telephone showed that none of the patients had any complaints about their bowel movements or had experienced incontinence or abdominal pain. Based on these results, a side-to-side Ileosigmoidostomy shunting surgery can be considered as an alternative to a subtotal colectomy ileorectal end-to-end anastomosis for the treatment of elderly patients with chronic constipation.

\section{CONFLICT OF INTEREST}

No potential conflict of interest relevant to this article was reported.

\section{REFERENCES}

1. Gallegos-Orozco JF, Foxx-Orenstein AE, Sterler SM, Stoa JM. Chronic constipation in the elderly. Am J Gastroenterol 2012;107: 18-25.

2. Soriano RP. Overview of palliative care and non-pain symptom management. In: Soriano RP, Fernandez HM, Cassel CK, Leipzig RM, editors. Fundamentals of geriatric medicine: a case-based approach. New York: Springer; 2007. p. 547-77.

3. Meiring PJ, Joubert G. Constipation in elderly patients attending a polyclinic. S Afr Med J 1998;88:888-90.

4. Nyam DC, Pemberton JH, Ilstrup DM, Rath DM. Long-term results of surgery for chronic constipation. Dis Colon Rectum 1997;40:273-9.

5. Gallagher PF, O'Mahony D, Quigley EM. Management of chronic constipation in the elderly. Drugs Aging 2008;25:807-21.

6. Eoff JC. Optimal treatment of chronic constipation in managed care: review and roundtable discussion. J Manag Care Pharm 2008;14(9 Suppl A):1-15.

7. Mohsen A, Wilkinson M. Current management options for chronic constipation. Prescriber 2007;18:23-38.

8. O'Donnell LJ, Virjee J, Heaton KW. Detection of pseudodiarrhoea by simple clinical assessment of intestinal transit rate. BMJ 1990; 300:439-40.

9. Heaton KW, Radvan J, Cripps H, Mountford RA, Braddon FE, Hughes AO. Defecation frequency and timing, and stool form in the general population: a prospective study. Gut 1992;33:818-24.

10. Hsieh C. Treatment of constipation in older adults. Am Fam Physician 2005;72:2277-84.

11. Basson MD. Constipation: practice essentials, background, pathophysiology [Internet]. New York: Medscape, LLC; c1994-2017 [cited 2017 Apr 11]. Availble from: http://emedicine.medscape. com/article/184704-overview. 